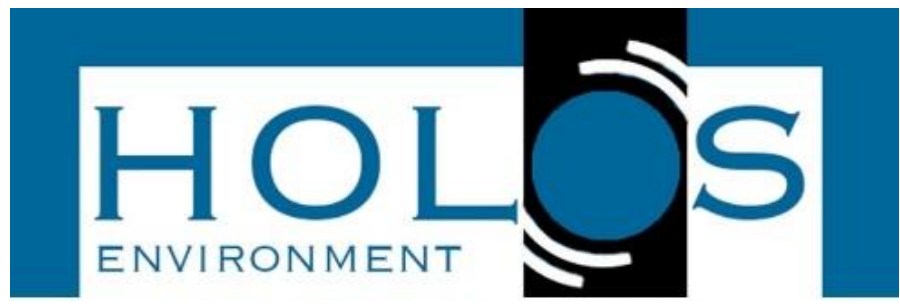

\title{
COMISSÃO DE MEIO AMBIENTE E QUALIDADE DE VIDA NA ESCOLA (COM- VIDA): UMA INVESTIGAÇÃO EM DOCUMENTOS OFICIAIS
}

\section{COMMITTEE ON THE ENVIRONMENT AND QUALITY OF LIFE AT SCHOOL (COM-VIDA): AN INVESTIGATION IN OFFICIAL DOCUMENTS}

\author{
Gabriela Costa Belasco ${ }^{1}$; Marcelo Damiano ${ }^{1}$; Yara Santucci Barreto ${ }^{1}$; \\ Juceli Aparecida Leme Mundo'; Taitiâny Kárita Bonzanini ${ }^{1}$
}

Artigo recebido em: 24/11/2019 e aceito para publicação em: 09/01/2020.

DOI: http://dx.doi.org/10.14295/holos.v20i1.12364

Resumo: Nesse artigo é apresentada uma investigação que enfocou, a partir de uma análise documental, os documentos "Formando COM-VIDA - construindo a Agenda 21 na escola" e "Educação Ambiental: aprendizes de sustentabilidade". Para a análise foram relacionadas as palavras: COM-VIDA, Políticas públicas, Educação, Educação ambiental, Práticas pedagógicas, Meio ambiente, Ensino, Jovens e Agenda 21, realizando-se contagem de ocorrências em ambos documentos, relacionando ainda discussões sobre a autoria dos documentos, assim como autores, natureza e contexto. Os documentos analisados tratam o tema de forma correspondente, com linguagem objetiva. Notou-se a estreita relação da Com-Vida com as políticas governamentais atuais, bem como a necessidade de novos documentos sobre o assunto com enfoque mais específico sobre estratégias de implantação do programa e que reforcem a necessidade de continuidade e desenvolvimento do projeto "Vamos Cuidar do Brasil com as Escolas" as quais a Com-Vida integra.

Palavras-chave: Com-Vida. Educação Ambiental. Meio Ambiente. Políticas Públicas. Agenda 21.

\begin{abstract}
In this article we present an investigation that focused, from a documentary analysis, the documents FORMANDO COM-VIDA - construindo a Agenda 21 na escola and Educação ambiental: aprendizes de sustentabilidade. For the analysis, the following words were related: COM-VIDA, Public policies, Education, Environmental education, Pedagogical practices, Environment, Teaching, Youth and Agenda 21, counting occurrences in both documents, also relating discussions about the authorship of documents, as well as authors, nature and context. The documents analyzed treat the theme in a corresponding way, with objective language. It was noted that Com-Vida's close relationship with current government policies, as well as the need for new documents on the subject with a more specific focus on strategies of implementation of the program and that reinforce the need for continuity and development of the project "Vamos cuidar do Brasil com as Escolas" which Com-Vida integrates.
\end{abstract}

Keywords: Com-Vida. Environmental Education. Environment. Public Policies. Agenda 21.

\section{INTRODUÇÃO}

A Educação Ambiental nas escolas pode ser determinante para a amenizar os problemas que, há anos, vêm sendo causados ao meio ambiente pela ação do ser

\footnotetext{
${ }^{1}$ Universidade de São Paulo (USP), São Paulo, SP E-mails: (gabriela.belasco@usp.br, marcelodamiano@usp.br, yarasantucci@usp.br, jucelimundo@usp.br, taitiany@usp.br)
} 
humano. As crianças representam as futuras gerações em formação e, como estão em fase de desenvolvimento cognitivo, supõe-se que nelas a consciência ambiental possa ser internalizada e traduzida de forma mais bem-sucedida quando comparadas aos adultos, já que ainda não possuem hábitos e comportamentos constituídos (CARVALHO, 2001).

São necessárias ações e políticas que visem conscientizar e sensibilizar as pessoas para a importância do papel que cada cidadão desempenha nesse processo.

As políticas públicas surgem da necessidade de mitigar os problemas da sociedade. A política da Educação Ambiental (EA) em conjunto com outras políticas, como a proposta da Comissão de Meio Ambiente e Qualidade de Vida na Escola (Com-Vida) pretendem enfrentar desafios como: o predomínio na sociedade contemporânea da cultura do consumo alienado, desconectado das consequências que o padrão de consumo predominante acarreta para os recursos naturais, para os ecossistemas e as diferentes comunidades que compõem a sociedade; a visão estreita da temática ambiental e suas relações com o modo de vida atual que a maioria dos jovens possui, implicando em baixa capacidade de análise, problematização e crítica sobre as questões ambientais; a falta de informação sobre as formas de produção de grande parte dos produtos consumidos, sobretudo os alimentos, acarretando o distanciamento entre o mundo da produção e o mundo do consumo.

A política de EA e, em particular, a Com-Vida, procuram reverter a postura que predomina na sociedade, no sentido indicado por Jacobi (2003):

A postura de dependência e de desresponsabilização da população decorre
principalmente da desinformação, da falta de consciência ambiental e de um
déficit de práticas comunitárias baseadas na participação e no envolvimento
dos cidadãos, que proponham uma nova cultura de direitos baseada na
motivação e na coparticipação da gestão ambiental (IDEM, pg. 4).

Assim, um dos objetivos das políticas deveria ser a valorização do aprendizado coletivo, onde os participantes constroem um espaço de discussão e reflexão sobre os problemas socioambientais.

Nesse sentido, pode-se refletir sobre alguns documentos como a Agenda 21, documento criado a partir da RIO-92, durante a Conferência das Nações Unidas sobre Meio Ambiente, realizada no Rio de Janeiro, que fornece as diretrizes gerais de como cuidar do planeta.

A Agenda 21 define os compromissos que 179 países assumiram de construir um novo modelo de desenvolvimento que resulte em melhor qualidade de vida para a humanidade e que seja econômica, social e ambientalmente sustentável. É um programa de planejamento participativo que visa o desenvolvimento sustentável, sendo um instrumento para que a Com-Vida seja desenvolvida através da integração de sociedade e escola, promovendo valores e ações ambientalmente saudáveis.

A Com-Vida, Comissão de Meio Ambiente e Qualidade de Vida na Escola, é um desdobramento da I Conferência Nacional Infantojuvenil pelo Meio Ambiente financiada e realizada em 2003 pelos ministérios da Educação e Meio Ambiente do Brasil, e visa estimular a formação de jovens educadores ambientais conscientes e 
atuantes perante suas comunidades a partir da aplicação da Agenda 21 em suas escolas.

A Com-Vida é formada por vários agentes envolvidos em questões ambientais, como estudantes, professores, funcionários, gestores e comunidade. O principal papel dessa Comissão é contribuir para um dia-a-dia participativo, democrático, animado e saudável na escola, promovendo o intercâmbio entre a escola e a comunidade.

Embora seja fruto de uma "estratégia pedagógica de educação difusa" do Ministério da Educação para "adensar conteúdos e trazer para a escola a dimensão política da questão ambiental" (BRASIL, 2012), seguindo o conceito dos Círculos de Aprendizagem e Cultura de Paulo Freire (1960) a Com-Vida seria aplicável a empresas, Organizações Não Governamentais, Comitês, Associações, igrejas ou quaisquer que sejam as comunidades interessadas em construir coletivamente soluções para mitigar suas próprias demandas e impactos emergentes relacionadas ao meio ambiente. Mas ao ser estruturada na escola, a Com-Vida faz desta um espaço de Educação Ambiental permanente e integrado com a comunidade escolar (BRASIL, 2012).

Foram estratégias em âmbito nacional para implementação de Com-Vidas no Brasil:

a) os Seminários de Formação de Professores e Estudantes em Educação Ambiental, eventos que objetivaram desenvolver o aprofundamento de conhecimentos locais e geraram publicações tais como Consumo Sustentável: manual de educação, Idec/MEC/MMA (2005) com temáticaseixo para nortear a implantação da Com-Vida nas escolas, e uma metodologia chamada Oficina de Futuro: instrumento voltado para a construção participativa por toda a comunidade de forma democrática das bases para o plano ação de cada Com-Vida em cada escola.

b) II Conferência Nacional Infantojuvenil pelo Meio Ambiente (2005/2006), que distribuiu a publicação Passo a Passo para a Conferência de Meio Ambiente na Escola, fomentando a formação de Com-Vidas nas escolas e hoje disponível, junto a diversas outras publicações, em site do Ministério da Educação e Cultura - MEC - http://conferenciainfanto.mec.gov.br.

O presente artigo trabalha a Com-Vida por levar em consideração que a temática ambiental tem se tornado assunto emergente no contexto escolar, envolvendo diversos sujeitos na promoção de questões relacionadas ao meio ambiente e desenvolvimento sustentável, porém ainda carece de aplicação efetiva dentro da escola.

Considerando que a Com-Vida propõe partir da comunidade escolar e abranger gradualmente a comunidade ao seu redor, podendo ser desenvolvida em diversas localidades, entende-se que é necessário adequá-la à realidade local, uma vez que envolve todas as particularidades de cada ambiente. A necessidade de se trabalhar a Com-Vida de maneira mais flexível também leva a alguns questionamentos: Existe um modelo único a ser seguido para a criação, estruturação e implantação da ComVida nas escolas? Os documentos que abordam a Com-Vida esclarecem os passos para sua estruturação? Como são retratados? 
Esse trabalho se propõe a responder essas questões, a partir de uma investigação sobre como essa Comissão é abordada em documentos oficiais da política atual de educação direcionada à comunidade escolar, em particular aos jovens.

\section{MATERIAL E MÉTODOS}

Nos estudos das ciências humanas e sociais a pesquisa documental ainda é pouco explorada (SÁ-SILVA et. al., 2009:2; LUDKE e ANDRÉ, 1986:38). No entanto, Cellard (2008:295) chama atenção para o valor que um documento pode ter para uma pesquisa, uma vez que, em alguns casos, estão entre as poucas fontes de informação disponíveis.

Tendo em vista a importância atribuída aos documentos para a pesquisa científica, a elaboração da pesquisa partiu da premissa de investigação da Comissão Com-Vida por meio da metodologia científica da análise documental em dois documentos produzidos pelo Governo Federal Brasileiro.

Foram selecionados dois documentos relacionados à Com-Vida presentes no site governamental de acesso público do Ministério da Educação e Cultura, o Portal do MEC: $\quad$ http://portal.mec.gov.br/programa-saude-da-escola/194-secretarias112877938/secad-educa\%C3\%A7\%C3\%A3o-continuada-223369541/13639educa\%C3\%A7\%C3\%A30-ambiental-publica\%C3\%A7\%C3\%B5es, a saber: "Formando COM-VIDA - Comissão de Meio Ambiente e Qualidade de Vida na Escola: construindo Agenda 21 na escola" e "Educação Ambiental: aprendizes de sustentabilidade".

A justificativa de escolha do primeiro texto incluiu o seu conhecimento por parte dos autores da pesquisa e por apresentar linguagem fácil e clara a respeito do procedimento de criação das Com-Vidas nas escolas. O segundo, por sugestionar a visão que o poder público tem das Com-Vidas, em se tratando de um documento de articulação governamental entre ministérios do meio ambiente e da educação para a promoção da EA, além de ambos apresentarem, dentre os textos que abordavam a Comissão presentes no site supracitado, o maior número das palavras-chave consideradas por esta pesquisa as mais significativas: Com-Vida, Educação Ambiental, Meio Ambiente, Políticas Públicas, Agenda 21.

\section{RESULTADOS E DISCUSSÃO}

Documento 1: Formando COM-VIDA - Comissão de Meio Ambiente e Qualidade de Vida na Escola: construindo Agenda 21 na escola. Ano de publicação: 2012. Autoria: BRASIL. Ministério da Educação.

Segundo Brasil (2012) a primeira proposta de se criar a Com-Vida surge a partir da I Conferência Nacional Infantojuvenil pelo Meio Ambiente, realizada pelo Ministério do Meio Ambiente em parceria com o Ministério da Educação, em 2003. A partir de então, as Com-Vidas foram sendo estruturadas por milhares de jovens de todo o país, mobilizados pelos Coletivos Jovens de Meio Ambiente: grupos informais de jovens e organizações juvenis, existentes em todos os estados brasileiros, que se mobilizam 
em torno das questões socioambientais e que tiveram participação fundamental na Conferência Nacional Infantojuvenil pelo Meio Ambiente.

A publicação, segundo Brasil (2012) apresenta uma nova versão da Com-Vida, ainda na Década da Educação para o Desenvolvimento Sustentável (2005-2014), uma iniciativa da ONU para o mundo inteiro, com a qual compartilha a percepção de que a Educação Ambiental trabalha com mudanças de valores e de atitudes para a construção de sociedades sustentáveis, justas, equitativas e felizes.

Trata-se de uma publicação oficial do Ministério da Educação e Cultura, o MEC, provindo, então, de fonte com alta legitimação neste espaço.

O texto tem por finalidade apresentar, em forma de cartilha, uma proposta, passo a passo, para se criar e implantar a Com-Vida - Comissão de Meio Ambiente e Qualidade de Vida na escola.

Nota-se a presença de uma linguagem didática para tratar a criação ou atuação da Com-Vida, direcionada ao público jovem.e às instituições escolares. Entre os elementos que didatizam o texto estão a linguagem simples, fácil e clara utilizada para apresentar a Com-Vida, seus objetivos e fundamentos e etapas para sua implementação nas escolas, uma vez que os textos não são muito longos, sendo, muitas vezes, utilizados tópicos para apresentar as ideias principais, como no exemplo a seguir: "estudantes são os principais articuladores da Com-Vida, podendo ser: • O delegado ou delegada eleitos na Conferência de Meio Ambiente na escola; • Grupos de estudantes que já realizam ações na área; • Grêmio estudantil preocupado com o tema" (BRASIL, 2012, p.13). São também utilizados termos e expressões que procuram atrair os leitores e remetê-los à sensação de pertencimento, tais como: "os projetos da Com-Vida integram o meio ambiente, nossas cidades e campos; as florestas, os animais, a água, o ar e a terra; como também a nossa vida, nosso corpo e as relações que temos com outras pessoas e outras culturas"(BRASIL, 2012, p.9) e também "somente em conjunto, com cooperação e solidariedade, será possível transformar nossa escola, nosso bairro e nosso planeta" (BRASIL, 2012, p.24). A publicação em formato de cartilha, contribui para a linguagem didática devido ao seu aspecto atrativo e instigante ao apresentar cores expressivas e diferentes formas e tamanhos de letras destacando as diversas partes do texto.

O documento também aborda a EA de maneira transdisciplinar, uma vez que propõe transcender os muros da escola, supondo ir além, ou a ultrapassagem daquilo que é próprio da disciplina (POMBO, 2005). As ideias do físico teórico Nicolescu (2000) também Fundador e Presidente do Centro Internacional de Pesquisas e Estudos Transdisciplinares (CIRET) nos dão embasamento para tal afirmação, quando define a transdisciplinaridade como um conceito que diz respeito àquilo que está ao mesmo tempo entre, através e além de qualquer disciplina, em que o objetivo é a compreensão do mundo presente. Tal fato pode ser comprovado por diversos trechos apresentados no texto, tais como: "esta publicação convida para a mobilização da comunidade escolar" (BRASIL, 2012, p.7); "para apoiar o fortalecimento da ComVida, trabalhamos com Agenda 21 na Escola - é isso mesmo, na escola como um espaço de educação permanente, bem junto e integrado com a comunidade escolar contando com a ajuda de uma metodologia divertida para a construção de projetos 
coletivos, chamada Oficina de Futuro" (BRASIL, 2012, p.8); "a Agenda 21 é um importante instrumento para ampliar as ações da Com-Vida, pois ela possibilita 0 diálogo com a comunidade da rua, do bairro, da quadra, do município e nos faz perceber que comunidades sustentáveis só acontecem por meio de parcerias" (BRASIL, 2012, p.8); "pensando bem, Com-Vidas podem ser criadas também em outros espaços e juntando gente de empresas, organizações da comunidade, Associações (de bairro, de moradores), em Organizações Não-Governamentais (ONGs), igrejas, Comitês de Bacias Hidrográficas" (BRASIL, 2012, p.13), sugerindo, portanto, uma proposta de EA que vai além das escolas e que atinge a comunidade e até mesmo o município no qual a escola está inserida.

O texto traz algumas sugestões de atividades a serem desenvolvidas nas ComVidas a partir da implementação da Agenda 21, uma agenda de compromissos e ações sustentáveis para o Século XXI, assinada durante a RIO-92. Tais atividades são parte de um projeto coletivo chamado "Oficina de Futuro" sendo abordadas na publicação as atividades que seguem: "Árvore dos Sonhos", "As Pedras no Caminho" e "Jornal Mural: viagem ao passado e ao presente".

A publicação, portanto, responde os objetivos colocados, pois permite que 0 leitor verifique quais são as indicações para a organização da Com-Vida na escola, a partir de uma proposta de passos, apresentados em etapas e mediante linguagem clara e objetiva. Entretanto, como sugestão para aperfeiçoamento da abordagem dessas Comissões, sugerimos que os documentos e publicações destinados às ComVidas tragam um maior número de sugestões de atividades a serem desenvolvidas, pois como evidenciado acima, no texto analisado foram abordadas apenas três sugestões de atividades e, considerando que as Com-Vidas atuam por tempo indeterminado, são necessárias diversas práticas e ações para sua promoção. Sugerimos, também, que os novos documentos e publicações abordem métodos para avaliação das atividades e ações desenvolvidas nas Com-Vidas, uma vez que é necessário o acompanhamento da EA e a verificação de sua efetivação na escola e comunidade escolar.

Documento 2: Educação Ambiental: aprendizes de sustentabilidade. Ano de publicação: 2007. Autores: Secad/MEC.

Desde 2004, então governo Lula, a Secad/MEC passou a executar políticas públicas voltadas ao ensino de EA e em 2007 criou os Cadernos Secad com fins a explicar e justificar essas diretrizes - sendo este caderno por nós selecionado para análise documental o primeiro de oito exemplares - com conteúdos informativos e formativos voltados a professores, gestores, profissionais da educação e parceiros institucionais que enfocaram sobretudo princípios de igualdade social e educação ambiental.

Segundo o documento analisado, a Conferência Nacional Infantojuvenil pelo Meio Ambiente, promovida pelo projeto Vamos Cuidar do Brasil com as Escolas, é o veículo para a formação das Com-Vidas nas escolas. Sobre as CNIJMA I e II realizadas respectivamente em 2003 e 2005, foram localizados dados na página 47 do documento a partir dos quais pôde-se elaborar as seguintes análises estatísticas:

- Redução próxima a 25\% de escolas participantes na II Conferência; 
- $46 \%$ das escolas participantes da I Conferência não participaram da II Conferência;

- Redução próxima a 33\% de pessoas participantes na II Conferência;

- Redução próxima a 17\% de municípios participantes na II Conferência;

- Aumento próximo a $45 \%$ de delegados na II Conferência.

Embora esses dados indiquem um desaquecimento da mobilização social que as CNIJMA I e II no período inicial do Projeto Vamos Cuidar do Brasil com as Escolas do qual a Com-Vida integra, não há menção clara no documento sobre o fato ou suas razões.

Segundo as informações contidas na página 46 do documento, a Secad/MEC e o DEA/MMA reduziram para menos de 1/3 o financiamento da II Conferência Nacional Infantojuvenil em relação à primeira, enquanto os patrocinadores aumentaram em aproximadamente $30 \%$ os recursos concedidos. No entanto, a soma final ainda manteve uma redução de mais de $25 \%$, o que talvez justifique a diminuição da participação de escolas na II Conferência. Segundo dados colhidos no sítio digital do MEC dedicado à essas Conferências (CONFERENCIAINFANTO, 2018), a III CNIJMA não teve comportamento diferente de sua antecessora e apenas na IV CNIJMA os números de escolas, participantes e municípios se recuperaram em relação à I CNIJMA, como pode ser observado na Tabela 1.

O documento analisado não contém informações sobre essa retração entre a primeira e última Conferências, tampouco dados que a justifiquem. Pelo fato dessa publicação como os demais cadernos Secad terem sido lançados em 2007, ou seja, dentro do referido período, pode-se deduzir que tenham sido parte de um esforço em alavancar essa política pública em contribuição ao ensino de EA.

Tabela 1 - Evolução das CNIJMA

\begin{tabular}{ccccc}
\hline & Ano & Escolas & Participantes & Municípios \\
\hline I CNIJMA & 2003 & 15.452 & 5.658 .877 & 3.461 \\
II CNIJMA & $2005 / 2006$ & 11.475 & 3.800 .000 & 2.865 \\
$\quad$ III & $2008 / 2009$ & 11.631 & 3.700 .000 & 2.828 \\
$\begin{array}{c}\text { CNIJMA } \\
\text { IV }\end{array}$ & $2013 / 2014$ & 16.538 & 5.193 .881 & 3.519 \\
CNIJMA & & & &
\end{tabular}

Fonte: http://conferenciainfanto.mec.gov.br/

Dados estatísticos em tabela situada na página 94 do documento, relativos à cada uma das três ações estruturantes para a EA nas escolas - Com-Vida, Coletivos Jovens de Meio Ambiente e Educação Chico Mendes, que integram conjuntamente o projeto Vamos Cuidar do Brasil com as Escolas - mostram números totais em âmbito nacional de indivíduos participantes das duas últimas, sendo que para a primeira esse dado é ausente na tabela, onde apenas é informado o número de escolas que formaram Com-Vidas em suas comunidades, num total de 4.121 unidades. Entretanto, um número médio de 230 indivíduos participantes das Com-Vidas por escola foi localizado na página 61 , de onde matematicamente pode-se deduzir que um número próximo a 1 milhão de indivíduos tenham participado de Com-Vidas em seus quatro 
primeiros anos de implantação, o que é bastante relevante diante das estatísticas levantadas na mesma pesquisa para as outras duas ações, onde 337.478 são os participantes da ação Educação Chico Mendes e apenas 838 é o número de membros dos Coletivos Jovens. Essas análises podem indicar uma vocação da Com-Vida para envolver a comunidade com o propósito do ensino de EA de uma forma socialmente mais abrangente e por isso com um impacto efetivo.

O texto desse documento como um todo, busca elucidar o propósito de enquadramento social na Educação Ambiental por meio do desenvolvimento de políticas públicas capazes de consolidar a visão sistêmica da sustentabilidade na sociedade partindo do fortalecimento da relação escola e comunidade, como o trecho reforça:

O público das COM-VIDAs varia em função de suas duas vertentes de atuação, comunidades e escolas; ora se refere à Comunidades de Aprendizagem sobre Meio Ambiente e Qualidade de Vida (MMA), ora à Comissão de Meio Ambiente e Qualidade de Vida na Escola (MEC). A COMVIDA na escola tem como fio condutor a proposta de maior aproximação entre escola e comunidade por meio da temática socioambiental (BRASIL, 2007, p. $31)$.

Nota-se noutras partes do documento uma tendência clara em favorecer as contribuições sociológicas da Educação Ambiental (p. 18) em detrimento das de cunho ambiental. São usados termos como "enfrentamento político", "sistemas sociais", "educação popular", "sujeitos (...) vítimas da injustiça ambiental" e "conteúdos biologizantes", este último como crítica à visão científica sem dialogar com as questões sociais, o que demonstra desconsiderar o encontro de Fritjof Capra com a então ministra do meio ambiente Marina Silva na ocasião de uma conferência ministrada pelo físico no III Fórum Social Mundial em Porto Alegre no ano de $2003 \mathrm{em}$ que expôs os fundamentos e finalidades da Alfabetização Ecológica e gerou pela primeira vez no Brasil a oportunidade de um debate diante da polarização de opiniões sobre Educação Ambiental (LAYRARGUES, 2003). O documento analisado não cita o encontro ou mesmo o evento internacional ocorridos em território brasileiro, contemporâneos à I CNIJMA, e proclama com ênfase a visão socioambiental como a maior justificativa para a Educação Ambiental, adjetivando a visão da dimensão ecológica da questão ambiental como "ingênua", "ambientalista" e "conservacionista". Dessa forma, acaba liquidada a validade do debate gerado pelo argumento de Capra e defensores da Alfabetização Ecológica que Layrargues ressalta quando refere-se à "importância do aprendizado das relações ecológicas, possibilitando a compreensão das conexões ocultas que regem a teia da vida", ou sobre "o paradigma reducionista da visão fragmentada da realidade" e "o pensamento sistêmico ou ecológico" (2003, p. 2), pontos altos desse modelo inquestionavelmente aceito mundialmente pela sua credibilidade científica.

Ambos documentos analisados estão relacionados, pois ambos tratam da Educação Ambiental direcionada a jovens em idade escolar. O primeiro documento assume o conceito de "cartilha", utilizando uma estética lúdica e linguagem didática, direcionado a aqueles que estão envolvidos diretamente em iniciativas de formação 
de grupos de jovens para atuar em EA. Já o segundo é um documento que apresenta uma política pública de Educação Ambiental, ou seja, define as diretrizes da política de EA voltada para os jovens. Está direcionado a um público mais amplo e engloba as relações entre o projeto Com-Vida e demais organizações da sociedade que tratam de questões diretamente relacionadas à EA ou que tenha correlação. Assim, há uma estreita relação entre os dois textos, sendo o primeiro um texto que detalha um subitem do segundo.

Em ambos documentos fica clara a preocupação com a Educação Ambiental levando em conta a visão de meio ambiente pelos jovens pela contagem de ocorrências dos termos e palavras-chave escolhidos (Tabela 2). Diante da importância em perspectiva de organização da Agenda 21 e a contribuição para formulação da Com-Vida, também escolhemos seu nome como palavra-chave deste artigo. Políticas públicas embora também com menor ocorrência foi escolhido por se tratar de uma definição para a Com-Vida, diante de teor sócio-político com que foi criada.

Tabela 2 - Termos e Palavras-chave destacados

\begin{tabular}{cc}
\hline Termos & Ocorrências \\
\hline Com-Vida & 81 \\
Políticas públicas & 44 \\
Educação & 778 \\
Educação ambiental & 458 \\
Práticas pedagógicas & 2 \\
Meio ambiente & 328 \\
Ensino & 112 \\
Jovens & 100 \\
Agenda 21 & 27 \\
\hline
\end{tabular}

A Com-Vida é apresentada nos documentos como uma medida conjugada com a Conferência Nacional Infanto-Juvenil e a Agenda 21 para estimular a formação de jovens educadores ambientais conscientes e atuantes perante suas comunidades.

O programa foi idealizado em resposta às deliberações da I Conferência Nacional Infantojuvenil pelo Meio Ambiente (I CNIJMA), realizada pelo Ministério do Meio Ambiente em parceria com o Ministério da Educação, em 2003, quando os estudantes envolvidos propuseram a criação de conselhos jovens de meio ambiente e a elaboração da Agenda 21 nas escolas do país (BRASIL, 2007, p. 35).

As Com-Vidas assumem nos textos um papel destacado como articulador das questões socioambientais, entrelaçando os propósitos da aprendizagem sobre o meio ambiente com os da qualidade de vida, já alinhavados pelos Ministérios do Meio Ambiente e da Educação, estimulando a autonomia e comprometimento dos alunos do Ensino Fundamental a tomar iniciativas quanto à prática de políticas ambientais no contexto escolar aproximando-as da comunidade, melhorando a qualidade de vida e contribuindo para formação da cidadania. 
Devido às suas características multidimensionais e interdisciplinares, a educação ambiental se aproxima e interage com outras dimensões da educação contemporânea, tais como a educação para os direitos humanos, para a paz, para a saúde, para o desenvolvimento e para a cidadania (BRASIL, 2007, p. 11).

A Com-Vida é também apresentada em trecho dedicado com seis páginas contínuas no segundo documento analisado como uma das três ações estruturantes do Programa Vamos Cuidar do Brasil com as Escolas desde 2004, junto com o Coletivo Jovem e Educação de Chico Mendes, propondo um conselho jovem para (re)aproximar a escola da comunidade e aplicar a Agenda 21 nas escolas conforme deliberado pela I Conferência Nacional Infantojuvenil pelo Meio Ambiente, primeiro eixo do programa, mas também desenvolver a EA nas escolas participando dos Projetos Políticos Pedagógicos e promovendo intercâmbios com outras Com-Vidas. Nesse mesmo trecho é apresentado como objetivo geral da Com-Vida:

Criar espaços estruturantes na escola para um dia-a-dia participativo, democrático, animado e saudável, promovendo o intercâmbio entre a escola e a comunidade, com foco nas questões socioambientais locais (BRASIL, 2007, p. 58).

O documento analisado ainda se refere às Com-Vidas como "espaços escolares democráticos", por integrarem vários atores sociais a partir do cenário escolar, que se originam sobretudo com os estudantes - apoiados pelos professores e funcionários - jovens que passam a atuar aos poucos junto a toda a escola e devem expandir para a comunidade local, com a qual se integram, para juntos encontrarem soluções para os problemas socioambientais locais detectados de forma participativa e dividirem responsabilidades. Por essa mesma formação orgânica, a Com-Vida não se restringe a uma estrutura de propriedade escolar, mas sim torna-se "palco" comunitário e "irradiador" da EA, integrando-se ao princípio "pensar global e agir localmente" do sociólogo alemão Ulrich Beck.

\begin{abstract}
A Agenda 21 foi apresentada como um programa de ação global, propondo ações para um novo modelo de desenvolvimento, com o uso sustentável dos recursos naturais e preservação da biodiversidade, e pensando a qualidade de vida das futuras gerações por meio da educação. A Carta Brasileira para a Educação Ambiental cobrou o compromisso do poder público federal, estadual e municipal para o cumprimento da legislação brasileira na inserção da educação ambiental em todos os níveis de ensino. O Tratado de Educação Ambiental para Sociedades Sustentáveis e Responsabilidade Global lançou o compromisso da sociedade civil para a construção de um modelo mais harmônico de desenvolvimento (EFFTING, 2007, p.7,8).
\end{abstract}

\title{
4 CONCLUSÕES
}

A Comissão de Meio Ambiente e Qualidade de Vida na Escola (Com-Vida), criada em 2003, a partir de conferências infantojuvenis promovidas pelo MEC, e o $3^{\circ}$ programa Escolas Sustentáveis estão sendo considerados essenciais para o 
fortalecimento das políticas de educação. A concepção da Educação Ambiental presente nos documentos analisados pode ser considerada sistêmica. Ela propõe uma visão que integre os elementos do meio ambiente, cidade, campo, florestas, água, ar, alimentos, animais, chamando atenção para o fato de que as pessoas também são parte deste todo. As Comissões Com-Vida seriam as organizações responsáveis por pensar a integração da escola com a comunidade a partir da identificação e discussão de problemas socioambientais, bem como a elaboração de propostas de ações coletivas na comunidade e na escola. Percebe-se que as Comissões Com-Vida são espaços de aprendizado sobre EA, mas também espaços de aprendizado sobre participação e atuação em grupo, com práticas locais usando instrumentos de discussão, conscientização e ação participativa e com movimentos institucionais por meio de conferências.

Os tópicos abordados nos documentos contêm questões atuais da Com-Vida, tratadas durante a I Conferência Nacional Infantojuvenil pelo Meio Ambiente, realizada pelo Ministério do Meio Ambiente em parceria com o Ministério da Educação, no ano de 2003. A partir de então, as conferências continuam acontecendo, o que vem permitindo o fortalecimento das Com-Vidas e a criação da Comissão em outras escolas. A organização das conferências infanto-juvenis mostrou-se importante para a manutenção e ampliação das Comissões Com-Vida em âmbito nacional. Por outro lado, a dependência de financiamento governamental para a realização das Conferências Nacionais expôs uma vulnerabilidade da política, uma vez que a diminuição de recursos destinados a estes eventos acarretou diretamente na redução do número de participantes.

Outro aspecto a ser destacado e está relacionado é a continuidade ou não desta política, pois ela é função da política partidária que prevalece em determinado momento, ou seja, depende daqueles que, em determinado momento, são os responsáveis pelos ministérios e pela continuidade, ou não, das políticas públicas, dos projetos e ações. Na primeira década deste século, as políticas tiveram continuidade, pois os governos que se sucederam tinham a mesma orientação política. Nos últimos anos, com a mudança de governo, a política sofreu uma descontinuidade, acarretando no atraso da realização da Conferência Nacional (IV CNIJMA). Também foi possível perceber uma redução no número de publicações destinadas à política das Comissões Com-Vida.

A política das Comissões Com-Vida indica um caminho para o desenvolvimento da cultura de respeito ao meio ambiente e de uma sociedade mais sustentável. Apesar de idealizadas para a comunidade escolar e estar em fase de expansão, as experiências bem-sucedidas sugerem que políticas análogas possam ser propostas em outros espaços da sociedade.

\section{AGRADECIMENTOS}

Agradecemos ao corpo docente do Programa de Pós-Graduação em Rede Nacional para Ensino das Ciências Ambientais (PROFCIAMB- USP). 


\section{REFERÊNCIAS}

BRASIL. Constituição (1988). Constituição da República Federativa do Brasil. Brasília, DF: Senado, 1988. 292 p. Disponível em:

https://www.senado.leg.br/atividade/const/con1988/CON1988 05.10.1988/CON1988.asp. Acesso em 24 de jun. 2018.

BRASIL. Ministério da Educação. Secretaria de Educação Continuada, Alfabetização, Diversidade e Inclusão. Vamos cuidar do Brasil com escolas sustentáveis: educandonos para pensar e agir em tempos de mudanças socioambientais globais. Brasília, 2012. 49 p. Disponível em:

http://www.seduc.go.gov.br/documentos/nucleomeioambiente/material2013/caderno.pdf. Acesso em: 24 jun. 2018.

BRASIL. Ministério da Educação. Secretaria de Educação Continuada, Alfabetização, Diversidade e Inclusão. Comissão de meio ambiente e qualidade de vida na escola Com-Vida. Ministério do Meio Ambiente. Ministério da Educação. (Documentos técnicos, 10). 1.ed. Brasília, 2007a. 30 p. Disponível em

http://portal.mec.gov.br/index.php?option=com docman\&view=download\&alias=9921-doctecnico-10-Com-Vida\&category slug=fevereiro-2012-pdf\&ltemid=30192. Acesso em: 24 jun. de 2018.

BRASIL. Ministério da Educação. Secretaria de Educação Continuada, Alfabetização, Diversidade e Inclusão. Educação ambiental: aprendizes de sustentabilidade. Brasília, 2007b. 109 p. Disponível em http://portal.mec.gov.br/dmdocuments/publicacao2.pdf. Acesso em 24 de jun. 2018.

BRASIL. Ministério da Educação. Secretaria de Educação Continuada, Alfabetização, Diversidade e Inclusão. Formando Com-Vida - Comissão de Meio Ambiente e Qualidade de Vida na Escola: construindo Agenda 21 na escola. Brasília, 2004. 42 p. Disponível em http://www.mma.gov.br/estruturas/educamb/ arquivos/Com-Vida.pdf. Acesso em: 24 Jun. 2018.

BRASIL. Ministério da Educação. Secretaria de Educação Continuada, Alfabetização, Diversidade e Inclusão. Consumo Sustentável: manual de educação. Brasília: Consumers International, 2005. 160 p. 1. Disponível em https://edisciplinas.usp.br/pluginfile.php/2648897/mod resource/content/1/Consumo Sustent avel.pdf. Acesso em: 24 Jun. 2018.

CARVALHO, I.C.M. Qual educação ambiental?: elementos para um debate sobre educação ambiental e extensão rural. Agroecologia e Desenvolvimento Rural Sustentável, Porto Alegre, v. 2, n. 2, p.43-51, abr./jul. 2001. Quadrimestral. Disponível em http://www.mma.gov.br/estruturas/educamb/ arquivos/qual educacao ambiental 20.pdf. Acesso em 24 de jun. 2018.

CELLARD, A. A análise documental. In: POUPART, J. et al. A pesquisa qualitativa: enfoques: epistemológico e metodológicos. Petrópolis, Vozes, 2008, p. 295-316.

EFFTING, T.R. Educação ambiental nas escolas públicas: realidade e desafios. 2007. 90 f. Monografia (Especialização) - Curso de Planejamento Para o Desenvolvimento Sustentável, Universidade Estadual do Oeste do Paraná, Marechal Cândido Rondon, 2007. 
GROHE, S.L.S. Escolas Sustentáveis: três experiências no Município de São Leopoldo. 2015. 136 f. Dissertação (Mestrado) - Curso de Pós Graduação em Educação, Pontifícia Universidade Católica do Rio Grande do Sul, Porto Alegre, 2015.

JACOBI, P. Educação ambiental, cidadania e sustentabilidade. Cad. Pesq. São Paulo, n. 118, p. 189-206, Mar. 2003 . Disponivel em:

http://www.scielo.br/scielo.php?script=sci arttext\&pid=S0100-

15742003000100008\&lng=en\&nrm=iso. Acesso em: 27 Out. 2017.

http://dx.doi.org/10.1590/S0100-15742003000100008.

LAYRARGUES, P. P. O cinismo da reciclagem: o significado ideológico da reciclagem da lata de alumínio e suas implicações para a educação ambiental. In: LOUREIRO, Carlos Frederico B.; LAYRARGUES, Philippe Pomier; CASTRO, Ronal de Souza (Orgs.).

Educação ambiental: repensando o espaço da cidadania. São Paulo: Cortez, 2002. p. 179-219.

Determinismo biológico: o desafio da alfabetização ecológica na concepção de Fritjot Capra. In: ENCONTRO DE PESQUISA EM EDUCAÇÃO AMBIENTAL, 2., 2003. [Anais...]. Rio Claro, UFSCAR. 2003. Disponível em:

http://www.epea.tmp.br/epea2003 anais/pdfs/plenary/27.pdf. Acesso em: 26 jun. 2018.

LÜDKE, M; ANDRÉ, M. E.D.A. Pesquisa em educação: abordagens qualitativas. São Paulo: EPU, 1986.

NICOLESCU, B. Transdisciplinarity and complexity: Levels of reality as source of indeterminancy. Bulletin interactif du CIRET (Centre de Recherche et Etudes Transdisciplinarité, 15, 71-75, 2000.

POMBO, O. Interdisciplinaridade e Integração dos saberes. Laboratório Interdisciplinar sobre Informação e Conhecimento, v.1, n.1, Março 2005, pp. 3 -15, 2005. Disponível em: http://revista.ibict.br/liinc/index. php/liinc/article/viewFile/186/103.

SÁ-SILVA, J. R.; ALMEIDA, C. D. de; GUINDANI, J. F. Pesquisa Documental: pistas teóricas e metodológica. Rev. Bras. de Hist. \& Ciências Sociais, v. 1, n. 1, jul, 2009. 